\title{
Microscopical speciation analysis with laser microprobe mass spectrometry and static secondary ion mass spectrometry ${ }^{1}$
}

\author{
L. Van Vaeck, A. Adriaens*, F. Adams \\ University of Antwerp (UIA), Department of Chemistry, Universiteitsplein 1, B-2610 Antwerpen, Belgium
}

Received 25 May 1997; accepted 18 December 1997

\begin{abstract}
This paper presents a set of data which compares the potential and limitations of laser microprobe mass spectrometry (TOFLMMS and FT-LMMS) and static secondary ion mass spectrometry (S-SIMS) for inorganic speciation at a microscopical level. In general LMMS yields prominent signals of adduct ions consisting of the intact molecule combined with a stable ion, which allows a direct identification of the analyte. S-SIMS also yields abundant diagnostic signals to specify the molecular composition. However, adduct ions are not always present, which means that the identification often relies on fingerprinting. Results further indicate that the potential and the application area of S-SIMS and FT-LMMS are complementary to one another. (C) 1998 Elsevier Science B.V.
\end{abstract}

Keywords: Laser microprobe mass spectrometry; Static secondary ion mass spectrometry; Inorganic speciation; Molecular identification

\section{Introduction}

Speciation analysis is now receiving a considerable amount of attention in analytical chemistry. It can be performed at different information levels and therefore the aims are usually defined in different ways by various practitioners. For instance, speciation can concern the determination of the oxidation state of an element or it can also involve the identification of organic or inorganic molecules in nature.

The measurement of element ratios allows the deduction of the molecular composition of pure substances on a first level. The identification of individual components, however, becomes at this level, almost impossible for mixtures. A second level of speciation

\footnotetext{
* Corresponding author.

This paper was published in the Special Issue devoted to Speciation.
}

information involves the detection of molecule specific signals. Methods such as IR and Raman spectroscopy, electron spectroscopy for chemical analysis (ESCA), etc., provide data concerning the kind of chemical bond or even the functional groups present in the sample. Also here, the problem with individual constituents persists when mixtures are analyzed. Therefore, there is a need for chemical analysis methods based on the detection of signals referring to intact molecules. In this respect, mass spectrometry combined with a suitable ionization method becomes a method of choice. The process of mass analysis is inherently sensitive and ensures a unimolecular behavior of the generated ions. A wide range of ionization methods exists, applicable to samples in the gas phase as well as directly to solid specimens. In this way, laser microprobe mass spectrometry (LMMS) and static secondary ion mass spectrometry (S-SIMS) are emerging as promising tools for direct analytical 
speciation of compounds at the microscopical level at or near the surface of solid materials.

The interaction of a focused laser or primary ion beam with the sample desorbs and ionizes the constituents at the surface. This results in emitted species which include ionized atoms or elemental ions, small cluster ions of which the composition does not directly reflect that of the original molecules, but also molecular adduct ions, i.e. intact molecules or molecules combined with a stable ion. This combination of atoms in the ions may exist in the sample as such or may result from the formation in the gas phase just above the sample between neutral molecules and co-desorbed ions. Depending on the internal energy of the emitted ions, further fragmentation may occur into structure-specific fragments.

The practical use of such direct speciation methods depends on several aspects. For instance, when the initial ionization primarily produces ions consisting of a single neutral molecule attached to a stable ion, then the original molecular composition becomes readily deducible from the mass spectrum. In such a case, in principle, there is no need to compare the resulting spectra with those of reference compounds. Only if the relationship between the mass spectral signals and the analyte composition is less straightforward because of the complexity of the ionization process, is fingerprinting, i.e. comparison with reference spectra, mandatory.

For several years now LMMS was used extensively in our laboratory for inorganic speciation analysis. The purpose of this paper is to compare its potential and limitations with S-SIMS for inorganic speciation at the microscopical level.

\section{Instrumentation}

The first commercial LMMS instruments used a time-of-flight (TOF) mass spectrometer, providing high transmission and inherent panoramic registration, i.e. a full mass spectrum is available for each laser interaction. The mass resolution attains about 500. Because it was assumed that ions were produced only during the laser pulse, continuous ion extraction from the source into the analyzer was applied. By the principle of TOF-MS, this restricts the measurement to the 'prompt ions', i.e. those formed during the laser pulse [1]. The ions which are formed over longer periods after the laser pulse, the so-called post-laser ionization, only give rise to a continuous background.

To overcome the restriction of the measurement of prompt ions and the limited mass resolution in TOFLMMS, high mass resolution LMMS instruments using a Fourier transform mass analyzer (FT-MS) were recently developed [2-4]. In this laboratory, an instrument with single FT-MS cell and an external source was developed in collaboration with the manufacturer Spectrospin (Fällanden, $\mathrm{CH}$ ). A full description of this instrument is given elsewhere [5]. It is now commercialized as MicroFocus (iid) (Bruker Instruments, Billerica, MA). Ionization is performed by a high power laser beam at $266 \mathrm{~nm}$ which is focused to a spot of ca $5 \mu \mathrm{m}$. Mass resolution attains over 100000 routinely and the mass accuracy is better than $1 \mathrm{ppm}$. By combining an ion trap with an ion transport system (from the ion source to the FT-MS cell), the mass spectral registration is no longer fully panoramic. Low $\mathrm{m} / \mathrm{z}$ ions formed in the source at the same moment as high $\mathrm{m} / \mathrm{z}$ ions will arrive sooner in the cell because of the higher acceleration they receive and their flight in field-free regions of the ion transport system. Because of the reflection against the second trapping plate, ions can be trapped simultaneously in the cell on the condition that their $\mathrm{m} / \mathrm{z}$ values range is within a factor 2.5 . However, whenever ions are formed over longer periods after the laser pulse, the low $\mathrm{m} / \mathrm{z}$ ions formed subsequently to the pulse are measured together with high $\mathrm{m} / \mathrm{z}$ ions formed during the laser pulse. As a result, relative intensities of different ions may vary depending on the setting of the gate time ( $T_{\text {gate }}$ ), i.e. time after the laser pulse during which ions are allowed to enter the cell. This causes the different fractions of the initial ion population available in the source to be sampled in a time resolved manner.

The SIMS technique is based on the interaction of primary ions in the keV range with the surface components of solids. Depending on the sputter and vacuum conditions, a distinction is made between dynamic and static SIMS. S-SIMS uses a low primary ion current density so that each molecular microenvironment is hit by only one primary ion. As a result, only the outer monolayer at the surface is analyzed and the yield of high $\mathrm{m} / \mathrm{z}$ cluster ions is maximized [6]. S-SIMS has in the past been used 
Table 1

Main instrumental and analytical features of FT-LMMS and S-SIMS

\begin{tabular}{llc}
\hline & FT-LMMS MicroFocus (Bruker Instruments) & S-SIMS TOF-SIMS IV (Cameca) \\
\hline Mass spectrometer & Fourier transform & time-of-flight \\
Lateral resolution & $5 \mu \mathrm{m}$ & $100 \mathrm{~nm}$ \\
Mass resolution & $>100000$ & $300-10000$ \\
At lateral resolution & $5 \mu \mathrm{m}$ & $80 \mathrm{~nm}-0.3 \mathrm{~mm}$ \\
Imaging & - & + \\
Mass analysis & panoramic in limited range & panoramic \\
Information depth & $10-50 \mathrm{~nm}$ & monolayer \\
Mass range (amu) & 5000 & $>10000$ \\
Energy input for ionization particles & $266 \mathrm{~nm}^{16}$ hotons & $\mathrm{keV}$ ions \\
Energy dose & $10^{6}-10^{10} \mathrm{~W} \mathrm{~cm} \mathrm{~cm}^{-2}$ & $<10^{13}$ ions $\mathrm{cm}^{-2}$ \\
Detection limit & $10^{8} \mathrm{molecules}^{-3}$ & $10^{21}-10^{15}$ atoms cm $^{-3}$ \\
\hline
\end{tabular}

with different types of analyzers such as quadrupoles or TOF analyzers. These days, TOF-SIMS instruments are gaining interest, because of their high transmission characteristics.

Table 1 surveys typical instrumental and analytical features of FT-LMMS and S-SIMS.

\section{LMMS for speciation analysis}

The mass spectra from a given analyte recorded by TOF and FT-LMMS show minor to even major differences with respect to the nature of the detected ions as well as to the relative intensities. This is not entirely surprising. It must be realized that the interaction of a focused laser with a solid at a given power density yields a specific ion population in the ion source. Ideally, the fraction of the initial ion population which will reach the detector has an identical relative composition. However, in practice discrimination always occurs because of the characteristics of the ion optics in the mass analyzer, of the mass analyzer itself and of the detector system with respect to the initial energy of the ions and its distribution, the angular velocity distribution, the place and the time of ion formation. Specifically, TOF-LMMS only records the prompt ions while FT-LMMS also includes the post-laser ion contribution. Also TOF-LMMS can detect ions with relatively broad initial kinetic energy distributions; FT-LMMS only traps ions with a range of typically $1 \mathrm{eV}$. The time spent during mass analysis is typically up to $500 \mu \mathrm{s}$ in TOF-LMMS and over $500 \mathrm{~ms}$ in FT-LMMS [1].
A systematic analysis of several inorganic substances by FT-LMMS was performed to define the relationship between the mass spectral signal pattern and the original molecular composition. It has revealed that a rather simple scheme can be applied to deduce the molecular composition from the mass spectrum. Fig. 1 schematizes these systematics. Roughly, for inorganic salts, a major signal in the positive or negative ion mode, refers to the intact molecule combined with the original cation or anion of the salt. This particular ion is readily recognized because it yields an intense signal in the low $\mathrm{m} / \mathrm{z}$ range. For oxides, such adducts occur, or simply the radical molecular ions, e.g. $\mathrm{Bi}_{2} \mathrm{O}_{3} \cdot \mathrm{Bi}^{+}$for $\mathrm{Bi}_{2} \mathrm{O}_{3}$, $\mathrm{MoO}_{3}^{-}$for $\mathrm{MoO}_{3}$. Using the simple scheme in Fig. 1 enables the identification of an unknown analyte molecule even in the absence of reference spectra. The high mass resolution and mass accuracy capabilities of FT-LMMS further contribute to make the assignment of the detected signals almost unambiguous.

The database of a number of compounds also allows deduction of tentative concepts about the predominant ion formation mechanisms. It is believed that a major fraction of the diagnostic adduct ions is formed by ion molecule interactions between the initially released neutral analyte molecules and the co-desorbed ions in the gas phase just above the sample [7].

Several publications describe the application of TOF-LMMS for pure inorganic substances such as binary salts $[8,9]$, oxides $[10-12]$ and oxysalts [8,12-15]. Particularly for oxides, TOF-LMMS 


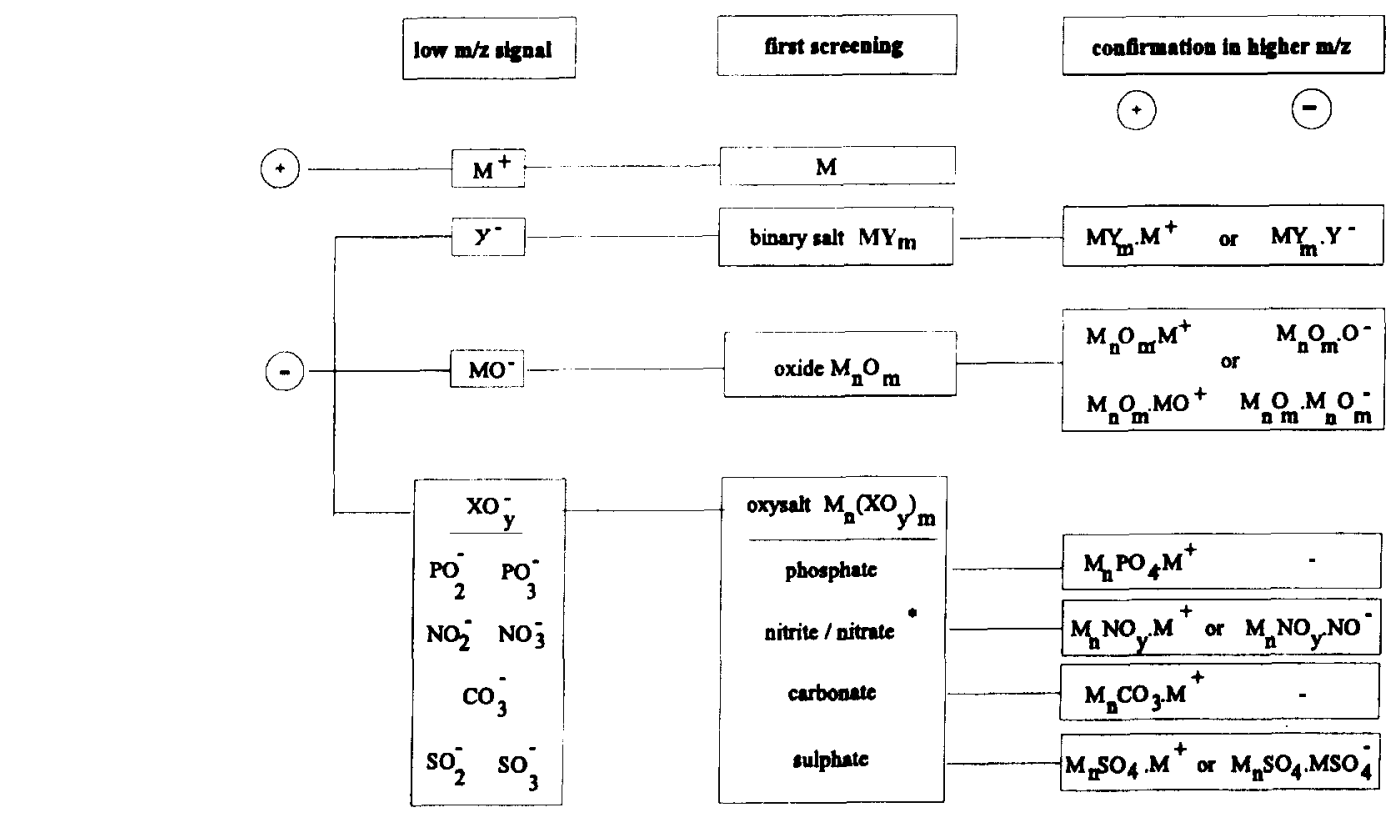

- Distinction between nitrate and nitrite depends on the ratios $\mathrm{NO}_{2}{ }^{-} / \mathrm{NO}_{3}{ }^{-}$and $\mathrm{M}_{\mathrm{n}} \mathrm{NO}_{3} \cdot \mathrm{NO}_{2}{ }^{-} / \mathrm{M}_{\mathrm{n}} \mathrm{NO}_{3} \cdot \mathrm{NO}_{3}{ }^{-}$.

Fig. 1. Scheme of direct speciation of inorganic compounds in FT-LMMS.

detects more extending series of cluster ions than FTLMMS. For oxysalts the relation between detected signals and the analyte composition is less straightforward for TOF-LMMS in comparison to FTLMMS. In addition, the adduct ions are often not seen in TOF-LMMS. As a result, the TOF-LMMS data are often used as fingerprints and a comparative approach using reference spectra is necessary to identify the analyte $[16,17]$. There is also a stronger influence of the applied laser power density in TOFLMMS as opposed to FT-LMMS [12,13]. Up until now the observed differences between TOF and FTLMMS spectra can be related consistently to the detection of the prompt ions only in TOF-LMMS and the integration recording of the prompt and delayed ions in FT-LMMS, but further research will be necessary to fully elucidate this aspect.

A recent review surveys the main data on speciation by LMMS in applications [18]. As to TOF-LMMS, a lot of research is performed in the field of biomedical analysis [19]. Typical examples involve the identification of phosphate or oxalate inclusions in renal tissues [20] and the detection of zirconium oxide particles in bone samples adjacent to prostheses [21]. Environmental applications comprise analysis of single aerosol particles [22,23]. Several case studies in the field of material analysis were reported to $[24,25]$. The use of FT-LMMS to perform speciation in problem solving involves material research applications as well as biomedical investigations $[26,27]$.

\section{Static SIMS for speciation}

Speciation studies using static SIMS (S-SIMS) are receiving a considerable amount of attention, primarily in applications involving polymer surfaces and organic compounds. In comparison, data for inorganic compounds have been, up to now, relatively limited. Much of the systematic work on inorganic molecules dates back to the seventies when the static SIMS technique came into use and essentially existed in establishing a relationship between S-SIMS spectra and the oxidation of monometallic surfaces. Results in this field have shown that relative intensities of $\mathrm{M}_{\mathrm{y}} \mathrm{O}_{\mathrm{x}}{ }^{ \pm}$ 
(M = metal) ions are able to monitor the degree of oxidation of the surface [28-30]. In addition, at about the same time, fingerprint spectra of a number of salts such as $\mathrm{Na}_{2} \mathrm{SO}_{4}$ and $\mathrm{Ag}_{2} \mathrm{SO}_{4}$ were investigated, with which it was demonstrated that fragmentation patterns depend on the electronegativity of the cations [31]. For metals with high electronegativity, fragmentation appears to be very low.

The advantage of static SIMS in speciation studies, as opposed to dynamic SIMS, is the fact that analyses are performed under a low flux ion bombardment of the surface $[30,31]$. This results in a relatively high yield of molecular ions, although the total ion yield may be much lower. The latter problem can be resolved by using a mass analyzer with high transmission, such as a time-of-flight mass spectrometer [32], therefore obtaining a good sensitivity.

The increasing use of S-SIMS has also created the necessity to compile spectra of standardized materials with which it is possible to make a comparison. The Handbook of Static SIMS by Briggs et al. [33] provides such a collection of static SIMS spectra. The majority of the spectra consists of organics and polymers, but metal oxides and binary salts were also taken up. This database is at present in full expansion and was published in the Wiley Static SIMS library [34] which is still updated on a regular basis.

The use of inorganic speciation with S-SIMS finds its applications in a number of fields, amongst others, environment in adsorption studies. Weng et al. [35], for instance, have investigated the fragmentation patterns and intensity species ratios of $\mathrm{Bi}$ and $\mathrm{Mo}$ in several pure bismuth molybdate phases. This investigation was part of a study in which silica-supported $\mathrm{Bi}-\mathrm{Mo}$ oxidation catalysts were analyzed. Results have shown that intensity ratios can be used to distinguish the nature of these phases.

Bentz et al. [36] used imaging capabilities of SSIMS to study and classify aerosol particles. Next to organic compounds, they were able to distinguish particles containing ammonium sulfate and sodium nitrate using intensity patterns. Spectra were compared with fingerprint spectra of pure inorganic compounds.

Groenwold et al. [37] have used S-SIMS for the speciation of gold cyanide on a carbon surface. Crown ethers were used for enhanced extraction.

\section{Speciation of pure substances}

In what follows, a comparison is made between FTLMMS and S-SIMS spectra of a few inorganic compounds. Fig. 2 illustrates the positive and negative ion mass spectra of molybdenum oxide recorded by FTLMMS. Looking at the positive ion mass spectra, the absence of the $\mathrm{MoO}_{3} \cdot \mathrm{MoO}^{+}$cluster at short $T_{\text {gate }}$ reflects the mass discrimination described earlier. However, the changing intensities of the lower $\mathrm{m} / \mathrm{z}$ ions $\mathrm{Mo}^{+}$vs $\mathrm{MoO}^{+}$and $\mathrm{MoO}_{2}^{+}$as a function of $T_{\text {gate }}$ ( $a$ and $b$ ) is caused by a difference in formation time, because there appears to be a significant difference in the low $\mathrm{m} / \mathrm{z}$ signals in spite of their limited $\mathrm{m} / \mathrm{z}$ difference. The results show the typical features one expects, and the speciation of the analyte is quite obvious. Following the strategy outlined in Fig. 1, the low $\mathrm{m} / \mathrm{z}$ ions in the positive mode suggest a molybdenum oxide by the presence of the $\mathrm{Mo}^{+}$signal and the accompanying signals, $16 \mathrm{~m} / \mathrm{z}$ units apart. Rather weak signals refer to the adduct of $\mathrm{MoO}^{+}$to the intact analyte molecules. For identification, the negative ion mode is most useful. The major signals are caused by the molecular anion and its combination with an intact neutral molecule. The $\mathrm{m} / \mathrm{z}$ range spans a factor 2.5 so that both ions can be trapped simultaneously when formed at the same moment in the ion source. In principle, using the nominal mass information and the isotope patterns, these data are already sufficient to identify the analyte.

The S-SIMS results of the same compound are depicted in Fig. 3. In fact the positive ion mode results yield quite similar information to that from LMMS data with major peaks originating from the $\mathrm{Mo}^{+}$and the $\mathrm{moO}^{+}$type cluster ions. Note the rather low intensity of $\mathrm{MoO}_{2}^{+}$while the $\mathrm{MoO}_{3} \cdot \mathrm{MoO}^{+}$ions are absent. In the negative mode, $\mathrm{MoO}_{3}^{-}$signals are clearly visible but carry only a relatively minor fraction of the total ion current. The majority is caused by $\mathrm{O}^{-}$and $\mathrm{OH}^{-}$. Noteworthy also, is the presence of the $\mathrm{MoO}_{3} \cdot \mathrm{MoO}_{3}^{-}$ ions although their intensity is weak. Overall, it is clear that the diagnostic information is equivalent to the one in LMMS. At the same time it is apparent that the high mass clusters, which are most useful for identification, carry a much smaller fraction of the total ion current than in LMMS.

This trend is confirmed by the FT-LMMS results for $\mathrm{Na}_{2} \mathrm{SO}_{4}$ given in Fig. 4. Low $\mathrm{m} / \mathrm{z}$ ions such as $\mathrm{Na}^{+}$, 

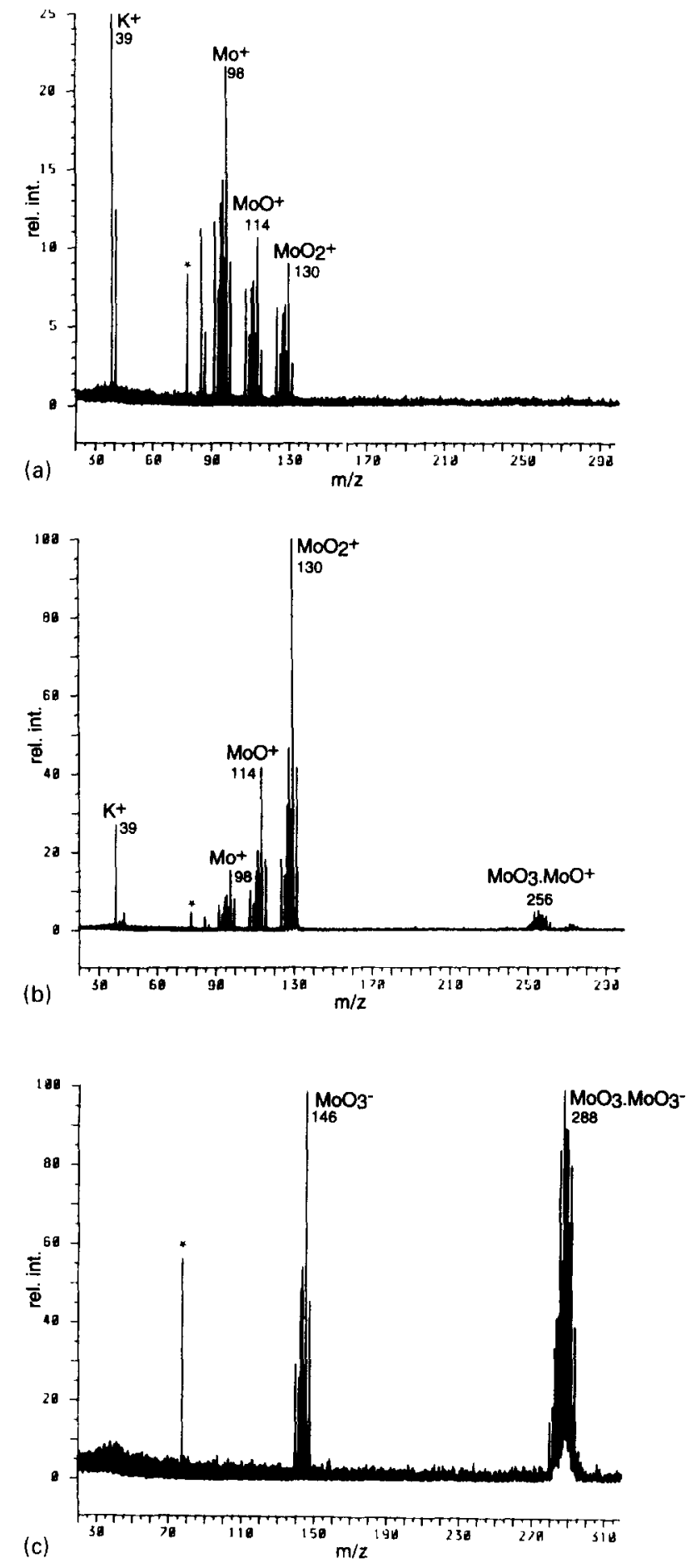

Fig. 2. Mass spectra of $\mathrm{MoO}_{3}$ recorded with FT-LMMS in the positive (a, b) and negative ion detection mode at values of $T_{\text {gate }}$ of $200 \mu \mathrm{s}$ (a), $400 \mu \mathrm{s}(\mathrm{b}, \mathrm{c})$ and a laser power density of $10^{8} \mathrm{~W} \mathrm{~cm}^{-2}$. 

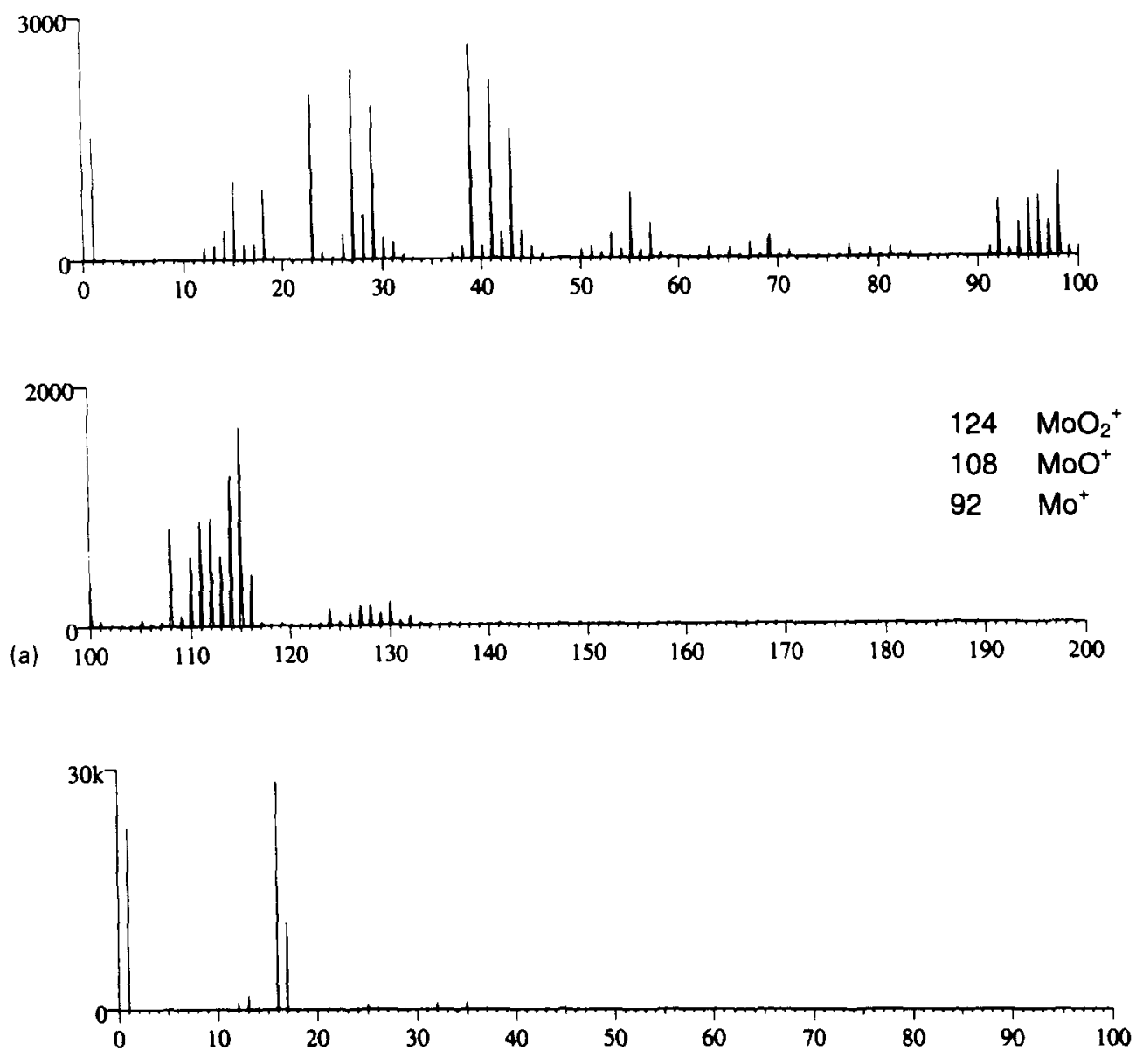

(b)

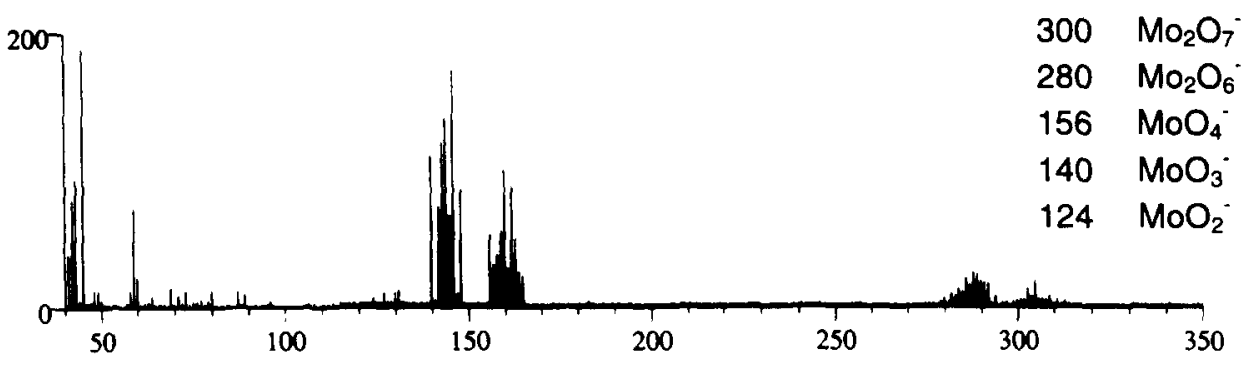

Fig. 3. S-SIMS results for Molybdenum (VI) oxide $\left(\mathrm{MoO}_{3}\right)$ [33]. Positive (a) and negative spectra (b) using Ga + bombardment at $22.5 \mathrm{keV}$ (a) and $27.5 \mathrm{keV}(\mathrm{b})$. The data are reprinted from [34] with permission from Wiley.

$\mathrm{Na}_{2} \mathrm{O}^{+}, \mathrm{SO}_{2}^{-}$and $\mathrm{SO}_{3}^{-}$identify the main building blocks of the oxysalt. However, molecular speciation can be based on the adduct ions $\mathrm{Na}_{2} \mathrm{SO}_{4} \cdot \mathrm{Na}^{+}$and $\mathrm{Na}_{2} \mathrm{SO}_{4} \cdot \mathrm{Na}_{2} \mathrm{SO}_{4}^{-}$. Note the chemically logical structure of the additional negative cluster ion $\mathrm{NaSO}_{4}^{-}$ giving a major signal. The presence of the $\mathrm{Cr}^{+}$and
$\mathrm{CrO}_{3}^{-}$signals is caused by the attack of the stainless steel sample holder by the sample.

The S-SIMS data are summarized in Table 2. The only significant positive ion detected is $\mathrm{Na}^{+}$. Also, in the negative ion detection mode, no high $\mathrm{m} / \mathrm{z}$ clusters are found so that molecular speciation in the strict way 
Table 2

Relative intensities obtained from S-SIMS spectra. Reprinted from [33] with permission from Wiley and Sons Ltd

\begin{tabular}{lllllllll}
\hline Oxyanion & Formula & $\mathrm{O}^{-}$ & $\mathrm{S}^{-}$ & $\mathrm{SO}^{-}$ & $\mathrm{SO}_{2}^{-}$ & $\mathrm{SO}_{3}^{-}$ & $\mathrm{SO}_{4}^{-}$ & $\mathrm{HSO}_{4}^{-}$ \\
\hline Thiosulfate & $\mathrm{S}_{2} \mathrm{O}_{3}^{2-}$ & 1.0 & 1 & 0.4 & 0.2 & 0.1 & 0.08 & - \\
Dithionite & $\mathrm{S}_{2} \mathrm{O}_{4}^{2-}$ & 27.5 & 1 & 3.3 & 3.5 & 2.5 & 0.3 & - \\
Pyrosulfite & $\mathrm{S}_{2} \mathrm{O}_{5}^{2-}$ & 4.5 & 1 & 0.1 & 0.1 & 0.07 & - & - \\
Dithionate & $\mathrm{S}_{2} \mathrm{O}_{6}^{2-}$ & 8.6 & 1 & 0.9 & 1.2 & 2.4 & 0.3 & - \\
Sulfite & $\mathrm{SO}_{3}^{2-}$ & 6.4 & 1 & 0.2 & 0.2 & 0.08 & - & - \\
Sulfate & $\mathrm{SO}_{4}^{2-}$ & 5.8 & 1 & 0.3 & 0.2 & 0.2 & 0.3 & - \\
Hydrogen sulfate & $\mathrm{HSO}_{4}^{-}$ & 15 & 1 & 0.7 & 1.7 & 7.0 & 3.0 & 8.0 \\
\hline
\end{tabular}

as defined is not possible. However, the relative ratios of the $\mathrm{O}^{-}$and $\mathrm{SO}_{\mathrm{n}}^{-}(\mathrm{n}=1-4)$, normalized to the $\mathrm{S}^{-}$peak, can be used to distinguish the whole series of oxyanions.

As a final example, the speciation of sodium nitrate and nitrite will be discussed. Apart from the low $\mathrm{m} / \mathrm{z}$ signals of $\mathrm{Na}^{+}$and $\mathrm{Na}_{2} \mathrm{O}^{+}$, FT-LMMS detects, in the positive ion mode, a series of cluster ions consisting of 1 to 4 neutral $\mathrm{Na}_{2} \mathrm{O}$ entities combined with $\mathrm{Na}^{+}, \mathrm{NaO}^{+}$ and $\mathrm{H}^{+}$. The sequence is interrupted by the ion at $\mathrm{m} / \mathrm{z}$ 163 which arises from $\mathrm{Na}_{2} \mathrm{O} . \mathrm{Na}_{2} \mathrm{O} . \mathrm{NaNO}^{+}$. Note that all the ion compositions were confirmed in high resolution with a mass accuracy within $1 \mathrm{ppm}$. The positive mass spectrum of sodium nitrate and nitrite are essentially the same. Also, in the negative mode the majority of signals is shared by both salts. Apart from $\mathrm{NO}_{2}^{-}$and $\mathrm{NO}_{3}^{-}$signals, diagnostic peaks in the higher $\mathrm{m} / \mathrm{z}$ range include $\mathrm{NaNO}_{4}^{-}(\mathrm{m} / \mathrm{z} \quad 101)$, $\mathrm{NaNO}_{2} \cdot \mathrm{NO}_{2}^{-}(\mathrm{m} / \mathrm{z} 115)$ and $\mathrm{NaNO}_{2} \cdot \mathrm{NO}_{3}^{-}(\mathrm{m} / \mathrm{z} 131)$. Interestingly, an additional signal at $\mathrm{m} / \mathrm{z} 147$ occurs for sodium nitrate and it arises from $\mathrm{NaNO}_{3} \cdot \mathrm{NO}_{3}^{-}$. The intensity is around 5\% at optimal $T_{\text {gate }}$ which is still sufficient to make the distinction between nitrate and nitrite on the condition that the analyte is the major component in the analyzed microvolume.

S-SIMS data on nitrate in the positive ion mode confirms the trend to generate $\mathrm{Na}_{2} \mathrm{O}^{+}$type clusters but the series is limited to the monomeric species. Again, the fraction of the total ion current carried by these clusters is very low as opposed to FT-LMMS. Additionally, ions at $\mathrm{m} / \mathrm{z} 108$ refer to $\mathrm{Na}_{2} \mathrm{NO}_{3}^{+}$and can be used for molecular speciation of nitrate in S-SIMS. Unfortunately, they are also detected in about the same relative fraction of the TIC for the nitrite, reflecting the greater degree of chemical conversion during the bombardment. In the negative mode, information is confined to $\mathrm{NO}^{-}, \mathrm{O}_{2}^{-}$and $\mathrm{NO}_{2}^{-}, \mathrm{NO}_{3}^{-}$signals in the following ratios for nitrate and nitrite respec- tively: 17:100:31:9 and 11:100:14:5. Taking these characteristic ratios into account, the analyte can be identified by these lower fragments, but no molecular speciation can be achieved. Note that the use of such fingerprints can be more sensitive to the instrumental operating conditions and the presence of other compounds in the analyzed microvolume as opposed to the deductive approach in LMMS.

The results presented here only aim at the assessment of the speciation capabilities of the methods when applied to pure products. In our experience, this information can be already very useful for numerous - but evidently not all - applications of problem solving in material sciences because the composition of the local microvolume often approaches the situation of a pure product. Much research is needed to accurately describe the speciation capabilities in complex mixtures. The relative sensitivity of given compounds will determine the mixing ratios in which they remain detectable under the same instrumental conditions, but there are little data on exact detection limits for each individual compound. Additionally, the composition and properties of the surrounding compounds or matrix may play a major role in the energy deposition and ionization mechanisms. For instance, UV absorption, reflection and refraction of the whole microvolume is important in LMMS while the high energy regime in S-SIMS is likely to induce intermolecular interactions. As a result, the bottleneck in this respect is however the preparation of adequate and representative mixtures.

\section{Conclusion}

S-SIMS and FT-LMMS emerge nowadays as two promising tools to obtain precise information 

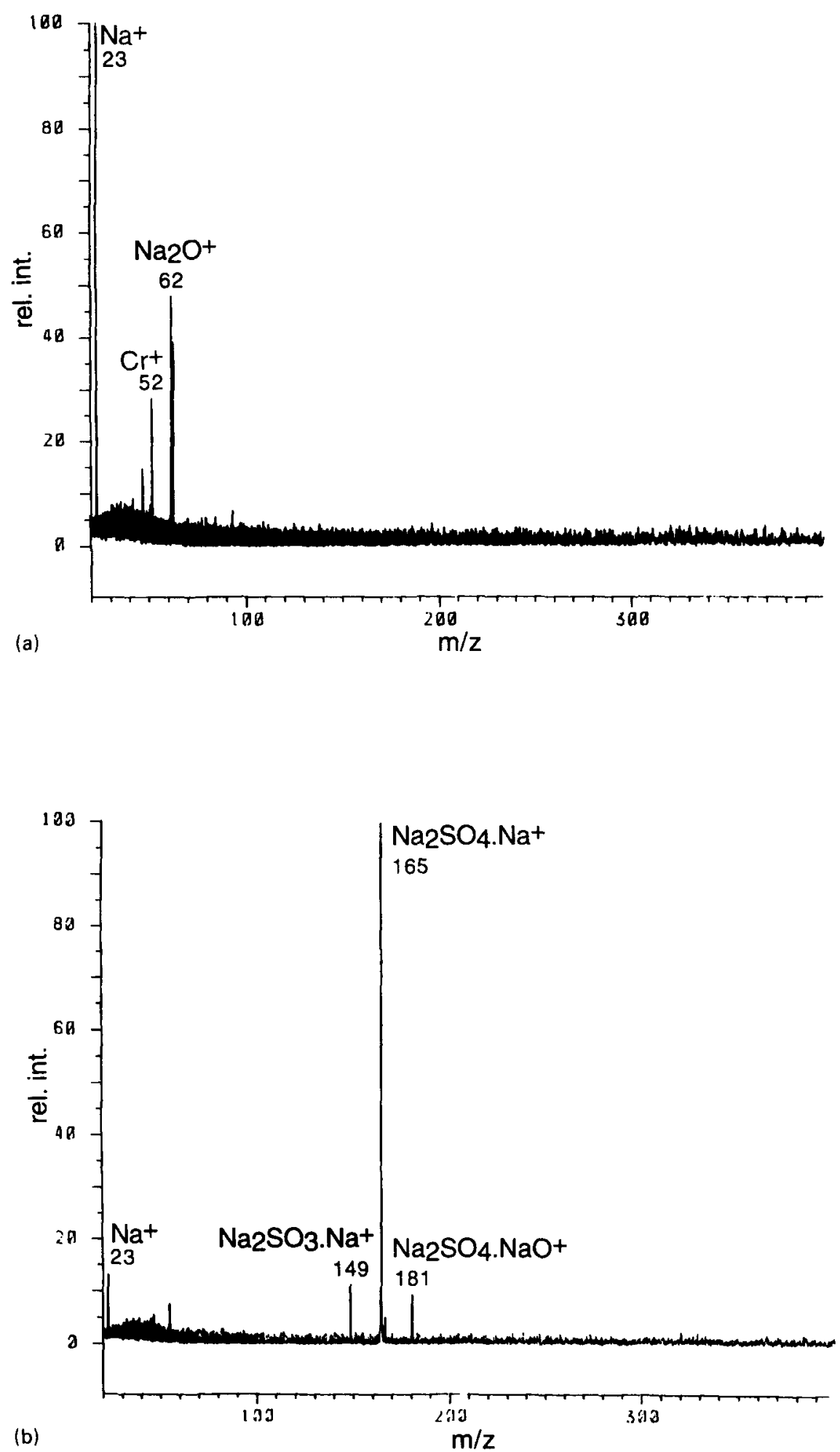

Fig. 4. Mass spectra of $\mathrm{Na}_{2} \mathrm{SO}_{4}$ recorded with FT-LMMS in the positive mode (a, b) and negative (c, d) detection mode at values of $T_{\text {gate }}$ of $200 \mu \mathrm{s}(\mathrm{a}, \mathrm{c}), 400 \mu \mathrm{s}(\mathrm{b}, \mathrm{d})$ and a laser power density of $10^{10} \mathrm{~W} \mathrm{\textrm {cm } ^ { - 2 }}$. 

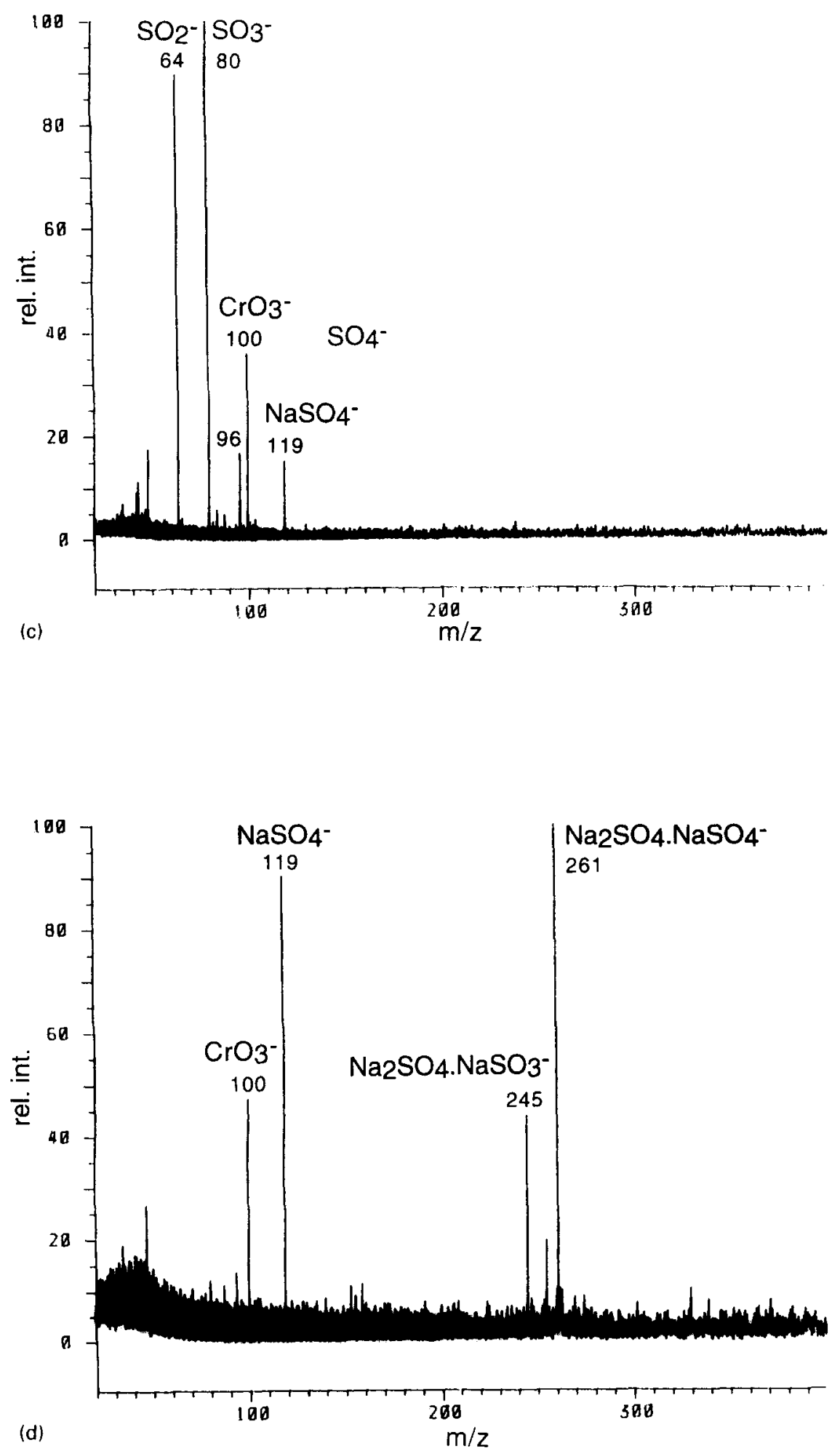

Fig. 4. Continued. 
concerning the molecular composition of the analyte at the surface of solids with a lateral resolution in the (sub-) $\mu \mathrm{m}$ range. Both methods are capable of identifying inorganic as well as organic substances. This paper has focused on the speciation of inorganic components. Data from FT-LMMS on pure compounds were compared with reference spectra from S-SIMS. It was demonstrated that LMMS usually yields prominent signals referring to the intact molecule combined with a stable ion. Additionally, low $\mathrm{m} / \mathrm{z}$ signals refer to specific fragments. As a result, LMMS data permit to perform the identification of the analyte on the level of direct speciation. Also, S-SIMS yield enough diagnostic signals to specify the molecular composition. However, the examples showed that the majority of the total ion current is carried by the low $\mathrm{m} / \mathrm{z}$ ions while the adduct ions are not always present. Nevertheless, the nature of the different fragments and their relative intensities enables one to identify the analyte. This means that identification often relies on fingerprinting while the purely deductive approach in LMMS permits identification without reference spectra.

At this stage, spectra of pure compounds were compared. There is little information on the analysis of complicated mixtures in general. To go from the qualitative identification of major components in the local microvolume to semi-quantitative or quantitative analysis, a great deal of additional research will be required. For instance, LMMS data point towards a major role of ion-molecule interactions in the 'selvedge' (gas phase just above the sample) to the detected ions. It can be anticipated that the unambiguity of the adduct ions may suffer when complex mixtures are involved. The situation is less clear in S-SIMS. The use of fingerprints for identification in mixtures depends on the reproducibility of the characteristic ions, qualitatively and quantitatively, for each component, and the absence of mutual interactions between the different constituents.

In conclusion, disregarding the speciation capabilities, the potential and the application area of S-SIMS and FT-LMMS is remarkably complementary. Because of the high resolution capacities and the systematical relationship between the signals and the structure, FT-LMMS seems more appropriate to deal with local analysis problems when little background information is available. However, the sensitivity and information depth of FT-LMMS practically excludes analysis of molecular monolayers. For such problems, S-SIMS becomes the method of choice. In addition, the recently developed reflectron type TOF-SIMS instruments with surface imaging capabilities on the sub-micron levvel allow novel applications in surface analysis and have resulted in a renewed interest [38].

\section{Acknowledgements}

L. Van Vaeck and A. Adriaens are indebted to the FWO, Belgium, as research director and senior research assistant, respectively. This text presents research results of FKFO/IIKW and the Belgian program on Interuniversity Poles of Attraction (IUAP III48) initiated by the Belgian State, Prime Minister's Office, Science Policy Programming.

\section{References}

[1] L. Van Vaeck, H. Struyf, W. Van Roy, F. Adams, Mass Spectrom. Rev. 13 (1994) 189.

[2] M. Pelletier, G. Krier, J.F. Muller, D. Weil, M. Johnston, Rapid Commun. Mass Spectrom. 2 (1988) 146.

[3] S. Ghaderi, Proceedings of the 36th ASMA Conference on Mass Spectrometry and Allied Topics, 1988, 1126.

[4] J.T. Brenna, W.R. Creasy, W. McBain, C. Soria, Rev. Sci. Instrum. 59 (1988) 873.

[5] L. Van Vaeck, W. Van Roy, H. Struyf, F. Adams, P. Caravatti, Rapid Commun. Mass Spectrom. 5 (1993) 323

[6] A. Benninghoven, B. Hagenhoff, E. Niehuis, Anal. Chem. 65 (14) (1993) 630A.

[7] H. Struyf, L. Van Vaeck, R. Van Grieken, Rapid Commun. Mass Spectrom. 10 (1996) 551.

[8] J. Dennemont, J.C. Landry, Mass spectrometric identification of inorganic substances by laser microprobe mass analysis, in: J.T. Armstrong (ed.), Microbeam Analysis, San Francisco Press Inc., San Francisco (1985) 305.

[9] E. Michiels, R. Gijbels, Mikrochim. Acta 111 (1983) 277.

[10] E. Michiels, R. Gijbels, Anal. Chem. 56 (1984) 1115.

[11] E. Poitevin, J.F. Muller, F. Klein, O. Déchelette, Analusis 17 (1989) 47.

[12] S. Gücer, L. Van Vaeck, F. Adams, Spectrochim. Acta 44B (1989) 1021.

[13] F.J. Bruynseels, R. Van Grieken, Anal. Chem. 56 (1984) 871.

[14] F. Bruynseels, Ph. Otten, R. Van Grieken, J. Anal. Atomic Spectrom. 3 (1988) 237.

[15] A. Hachimi, E. Poitevin, G. Krier, J.F. Muller, J. Pironon, F. Klein, Analusis 21 (1993) 77.

[16] I. Dierck, D. Michaud, L. Wouters, R. Van Grieken, Environ. Sci. Technol, 26 (1992) 802. 
[17] C.-U. Ro, I.H. Musselman, R.W. Linton, Anal, Chim. Acta 243 (1991) 139.

[18] L. Van Vaeck, H. Struyf, W. Van Roy, F. Adams, Mass Spectrom. Rev. 13 (1994) 209.

[19] S. Eeckhaoudt, L. Van Vaeck, R. Gijbels, R.E. Van Grieken, Scanning Microsc. Supplement 8 (1994) 335.

[20] A.H. Verbueken, R.E. Van Grieken, Anal. Chim. Acta 195 (1987) 97.

[21] I. Bos, B. Lindner, U. Seydel, R. Johannisson, E. Doerre, J. Henssge, U. Loehrs, Z. Orthop. 128 (1990) 73.

[22] F.J. Bruynseels, R. Van Grieken, Atmos. Environ. 19 (1985) 1969.

[23] S. Delmas, J.F. Muller, Analusis 20 (1992) 165.

[24] V.L. Kohler, A. Harris, E.R. Wallach, Light element analysis by LIMA, in: A.D. Romig, Jr, W.F. Chalmers (eds), Microbeam Analysis, San Francisco Press Inc., San Francisco (1986) 467.

[25] H.J. Heinen, R. Holm, S. Storp, Fresenius' Z. Anal. Chem. 319 (1984) 606.

[26] H. Struyf, W. Van Roy, L. Van Vaeck, R. Van Grieken, P. Caravatti, Rapid Commun. Mass Spectrom. 8 (1994) 32.

[27] M.M. Kockx, G.R.Y. De Meyer, H. Bortier, N. de Meyere, J. Muhring, A. Bakker, W. Jacob, L. Van Vaeck, A. Herman. Circulation 94 (1996) 1255.
[28] A. Benninghoven, A. Müller, Surf. Sci. 39 (1973) 416.

[29] H.W. Werner, Surf. Sci. 47 (1975) 301.

[30] J.C. Vickerman, A. Brown, N.M. Reed, Secondary Ion Mass Spectrometry. Principles and Applications, Clarendon Press, Oxford, 1989.

[31] A. Benninghoven, F.G. Rüdenauer, H.W. Werner, Secondary ion mass spectrometry. Basic concepts, instrumental aspects, applications and trends, in: P.J. Elving, J.D. Winefordner, I.M Kolthoff (eds), Chemical Analysis, vol. 86, Wiley, New York, 1987.

[32] R.J. Cotter, Anal. Chem. 64 (21) (1992) 1027A.

[33] D. Briggs, A. Brown, J.C. Vickerman, Handbook of Static Secondary Ion Mass Spectrometry, Wiley, Chichester, 1989.

[34] D. Briggs, J.C. Vickerman, The Wiley Static SIMS Library, Wiley.

[35] L.T. Weng, P. Bertrand, O. Tirions, M. Devillers, Appl. Surf Sci. 99 (1996) 185

[36] J.W.G. Bentz, J. Goschnick, J. Schuricht, H.J. Ache, J. Zehnphennig, A. Benninghoven, Fresenius J. Anal. Chem. 353 (1995) 603.

[37] G.S. Groenwold, J.C. Ingram, A.D. Appelhans, J.E. Delmore, Anal. Chem. 67 (13) (1995) 1987.

[38] A. Newman, Anal. Chem. News and Features Nov. 1 (1996) $683 \mathrm{~A}$. 